\title{
Collective Intuition: Implications for Improved Decision Making and Organisational Learning
}

\author{
Cinla Akinci (corresponding author) \\ University of St Andrews \\ School of Management \\ St Andrews, Fife \\ KY16 9RJ \\ United Kingdom
}

\section{Eugene Sadler-Smith}

University of Surrey

Surrey Business School

Guildford, Surrey

GU2 7XH

United Kingdom

Citation reference:

Akinci, C. and Sadler-Smith, E. 2018. Collective Intuition: Implications for Improved Decision Making and Organisational Learning, British Journal of Management. DOI: 10.1111/1467-8551.12269

Manuscript accepted: 16 October 2017

Published online: 3 January 2018 


\begin{abstract}
This article casts new light on the phenomenon of collective intuition through a study of decision making and organisational learning processes in senior management teams in police organisations. We contribute to intuition research, which has tended to focus its attention at the individual level, by studying intuition collectively in team settings. From a dual-process perspective, we investigate how expert intuition and deliberation affect decision making and learning at various levels of the organisation. Furthermore, we contribute to organisational learning research by offering an empirically-derived elaboration of the foundational " $4 \mathrm{I}$ framework' by identifying additional 'feed-forward' and 'feedback' loop processes, and thereby providing a more complete account of this organisational learning model. Bridging a variety of relevant but previously unconnected literatures via our focal concept of collective intuition, our research provides a foundation for future studies of this vitally important but under-researched organisational phenomenon. We offer theoretical and practical implications whereby expert intuitions can be developed and leveraged collectively as valuable sources of organisational knowledge and learning, and contribute to improved decision making in organisations.
\end{abstract}

Keywords: collective intuition; decision making; dual-processing; expert intuition; organisational learning; top management teams 


\section{Introduction}

Despite increased scholarly interest in the role of intuition in organisational decision making, there has been an almost exclusive focus on individual decision makers (Agor, 1986; Dane and Pratt, 2007; Dörfler and Ackermann, 2012; Miller and Ireland, 2005; Sadler-Smith and Shefy, 2004), thereby neglecting the study of collective intuition as an organisational phenomenon (Akinci and Sadler-Smith, 2012). In organisations, it is inevitable that intuitions are articulated and interpreted collectively, therefore for theoretical and practical reasons, there is a pressing need to understand intuition beyond the individual level and its implications for team decision making (Salas, Rosen and DiazGranados, 2010) and organisational learning (Crossan, Lane and White, 1999). To this end, we explored intuitive decision making as a collective process within senior police management teams, we do so in terms of its relational aspects and the associated behavioural and cognitive processes. We base our research in two currently unconnected theoretical frameworks. We use dual-process theory (Epstein, 1994) - emanating from the developments in the psychology of thinking and reasoning (Evans and Stanovich, 2013) and social cognition (Lieberman, 2007) - to better understand how expert intuition (rooted in domain-specific learning and experience, Salas et al, 2010) and deliberation (i.e. rational, analytical thinking) function jointly in collective decision making processes. Through the application of the '4I' organisational learning framework (Intuiting, Interpreting, Integrating, Institutionalising) (Crossan et al, 1999), we developed a deeper understanding of the phenomenon of collective intuition, captured in incidents of police teams' 'intuitive hits' and 'intuitive misses' (see Akinci, 2014).

Our research question was: how do teams use intuition collectively in decision making and consequently how does it lead to organisational learning? In addressing this question, we contribute to intuition and organisational learning research as follows: Firstly, dual-system theories focus on decision making at the individual level, however we sought to understand 
intuitive cognitions as a collective phenomenon in team settings amongst a societally important group of organisational actors. Secondly, the organisational learning literature posits a significant role for intuiting without due cognizance of the role of deliberating in a human information processing system that is essentially dual in nature; we therefore extended this literature by studying intuition in organisational learning from a dual-system perspective beyond the individual level of analysis. Consequently, our research contributed to the theoretical development of the 4I framework by identifying further feed-forward and feedback loop processes, thus offering a more complete account of this foundational organisational learning model. Finally, by shedding light on group-level intuitive decision making and organisational learning processes, we posit the notion of collective intuition, and suggest ways in which expert intuitions might be developed and leveraged collectively as valuable sources of organisational knowledge and learning.

\section{Research Context}

Decision making in police work takes place in an environment that is dynamic, uncertain and complex; decisions often have to be taken on the basis of incomplete or contradictory information, and police officers frequently use their 'best judgement' to provide a quick response. Consequently, decision making requires effective use of intuitive expertise grounded in officers' extensive knowledge, skills and abilities acquired in the policing domain. Within police organisations, Senior Management Teams (SMTs) are the most highprofile decision making group; they possess high levels of domain-specific expertise and experience, provide operational and strategic command functions, and control and direct a body vital to the functioning of civil society. Therefore, securing access to police SMTs provided an important and interesting setting to explore collective intuition at work through the study of a variety of intuitive hits and misses in planned operational and strategic decision making (in contrast to first-response decisions undertaken in front-line police work). 
Furthermore, although police organisations are, on the surface at least, command-and-control driven, the use of expert intuition as a form of non-canonical practice affords opportunities for organisational learning (see Easterby-Smith, 1997).

\section{Decision Making, Tacit Knowing and Organisational Learning}

The 'garbage can' model of organisational choice (Cohen, March and Olsen, 1972) dismisses traditional approaches to decision making envisaged as rational and underpinned by the logic of problem solving. Relatedly, Simon's (1955) concept of 'bounded rationality' has been foundational in developing the non-rational perspective in decision making research, laying the groundwork for insights into the decision maker's behaviour in complex, dynamic circumstances that involve high levels of uncertainty. Accordingly, behaviour in such situations coupled with the decision maker's inherently limited cognitive capacities, deviates from 'rational' choice and thereby involves intuition (Simon, 1987). For these and various other reasons, the intuitive perspective came into prominence in management research (Akinci and Sadler-Smith, 2012).

Further to this view, one of our key premises is that decision making is guided by forms of 'knowing' (e.g. expert intuition) where actors arrive at non-deliberative solutions to focal problems and that these cognitions provide opportunities for organisational learning. From a social constructionist perspective, such learning occurs in the social context of ‘communities of practice' (Brown and Duguid, 1991; Wenger, 1998) through the collective practice of a professional activity (e.g. policing) where knowledge is created, shared and utilised through conversations and interactions between people (Brown and Duguid, 2001; Gherardi and Nicolini, 2001; Lave and Wenger, 1991). In the SECI-ba model, 'ba' is the place where such interactions take place (e.g. the shared context of policing), and where information is interpreted to become knowledge through one's own experience or reflections on the experiences of others (Nonaka, Toyama, and Konno, 2000). The model emphasises 
that shared experience ('socialisation') is key to acquiring tacit knowledge, such as shared mental models or technical skills (Nonaka and Takeuchi, 1995). It is possible to acquire tacit knowledge (which in Nonaka's theory is 'tied to' intuition, see Nonaka and von Krogh, 2009, p. 635) without language but by observation, imitation and practice (e.g. master-apprentice relationship). Co-experience facilitates the creation of 'common perspectives' and 'externalisation' enables articulation of the shared tacit mental models into words and phrases, which finally crystallises into explicit concepts (Nonaka, 1994).

Nonaka and Takeuchi's (1995) interpretation of tacit knowledge as 'knowledge-notyet-articulated', i.e. as knowledge awaiting translation or conversion into explicit knowledge, is contradictory to Polanyi's (1962a) notion that in the act of knowing "articulation always remains incomplete" (p. 70). As such, this interpretation ignores the essential ineffability of tacit knowledge (see Russell, 1948), thus reducing it to what can be articulated (cf. Nickols' (2000) notion of 'implicit knowledge'). Tsoukas (2003) argued that tacit knowledge cannot be 'captured', 'translated', or 'converted' to explicit knowledge, but only displayed and manifested in what we do (e.g. Polanyi's (1962b) example of riding a bicycle). Accordingly, new knowledge comes about not when tacit becomes explicit, but when skilled performance is punctuated in new ways through social interaction (Tsoukas, 2001).

In a similar vein, the domains of intuiting and tacit knowing overlap but are not identical. While the outcomes of intuiting (i.e. intuitions or intuitive judgements) are clearly accessible to conscious thinking (and hence are articulable), how one arrives at them is not (Dane and Pratt, 2007). In this respect, all intuiting is tacit but not all tacit knowing is intuiting. Furthermore, although intuitions may be acquired tacitly, they can be interpreted and communicated as 'judgements' (Dane and Pratt, 2007, p. 40); whereas tacit knowing always has an 'inarticulable' dimension, captured succinctly in Polanyi's aphorism "we can know more than we can tell” (1966, p. 4). 
Intuition and organisational learning came together explicitly in the foundational 4I framework of Crossan et al (1999) wherein 'intuiting' is defined in Weickian terms as the "preconscious recognition of the pattern and/or possibilities inherent in a personal stream of experiences" (p. 525). Organisational learning occurs as a result of cognitions initiated by individuals' intuitions transcending to the group level by way of articulations and interactions between the group members through the processes of interpreting (cf. 'externalisation') and integrating, and which become institutionalised at the organisation level. The key premise of the 4I framework is that when individual and group learning becomes institutionalised, organisational learning occurs and knowledge is embedded in nonhuman repositories such as routines, systems, structures, culture, and strategy. The 4I framework is predicated on Weick's view of organisations as 'meaning' systems where perceptions are shared and cognitive maps are constructed (Daft and Weick, 1984; Weick, 1995) to make retrospective sense of what occurs (Weick, 1993). Sensemaking starts with noticing (Weick, Sutcliffe and Obstfeld, 2005) and entails the interplay of interpretation and action. Moreover, sensemaking has been explicitly linked to intuition via social psychology in the 'Sensemaking Intuition Model' (SIM) (Sonenshein, 2007) albeit limited to the moral judgement domain. In organisations, SMTs have a key role in, and are deemed responsible for, bringing together and interpreting information, and translating knowledge into action for the system as a whole (Daft and Weick, 1984) for learning to take place.

The most appealing feature of the $4 \mathrm{I}$ framework for our research is that it acknowledges intuition as part of a multi-level decision making and learning process thereby incorporating interactions between levels i.e. individual, group and organisation. However, it lacks an integrative approach that captures both conscious (deliberative) and subconscious (intuitive) elements of information processing. One of the contributions of our research is that it conjoins these developments in psychology grounded in 'dual process' or 'dual system' 
models (e.g. Evans, 2003, 2008), which are now to the fore in intuition research, with the original 4I framework of organisational learning which was inevitably lacking in this regard.

\section{Dual Process Theories of Reasoning and Judgement}

Dual-process theories posit that there are two contrasting but complementary modes of information processing underlain by two separate cognitive systems labelled generically as System 1 and System 2, with corresponding 'types' of processing Type 1 and Type 2 (Evans, 2003; Evans and Stanovich, 2013; Stanovich and West, 2000). Type 1 processing is contextually dependent, automatic, largely unconscious, associative, intuitive and implicit; it is relatively fast and non-deliberative, and undemanding in its use of scarce cognitive resources. In contrast, Type 2 processing is contextually independent, analytic, rule-based and explicit; it is relatively slow and deliberative, and makes greater demands on cognitive resources (Evans, 2003). Accordingly, conscious thought and individual behaviour are guided by the joint operations of the two systems (Epstein, 1994), with their relative influence being determined by various parameters including the nature of the situation, individual differences in thinking style, and degree of emotional involvement (Epstein, Pacini, Denes-Raj and Heier, 1996). Contrary to earlier views (e.g. Hayes and Allinson, 1994) there is no inherent incompatibility between deliberative and intuitive processing.

The view of 'intuition-as-expertise' (Sadler-Smith and Shefy, 2004) accords with Simon's idea that intuition emanates from experiences that previously called for rational analyses (Prietula and Simon, 1989): "intuition and judgement... are simply analyses frozen into habit and into the capacity for rapid response through recognition" (Simon, 1987, p. 63). As such, 'intuitive expertise' (Kahneman and Klein, 2009) based on pattern recognition (Klein, 1997) allows experienced decision makers to bypass the steps required in deliberative analysis (Simon, 1992). More recently, Dreyfus (2014) speculated that this type of intuiting draws on patterns stored in 'declarative' memory ('knowing that') using associative System 1; 
whereas an entirely different brain configuration, 'System 0', is better suited to represent experientially learned 'procedural' memory ('knowing how') and respond to familiar situations (i.e. intuitive expertise) by "knowing how to proceed" (p. 17) in a situation as opposed to information processing.

Experts' complex domain relevant schemas are built up through implicit and explicit learning processes (Dane and Pratt, 2007). While broader experiences are instrumental in the recognition of similar situations, these do not automatically convert into expertise. General experience relates to knowledge beyond one's domain of expertise (Sinclair, Ashkanasy, Chattopadhyay and Boyle, 2002), whereas professional expertise is domain specific, and comprises different types of knowledge and skills inherent in a specific field (Van der Heijden, 2000). Thus, complex schemas developed in one's area of expertise are more likely to lead to effective decisions in that domain but are unlikely to be transferable.

\section{Collective Cognition in Teams}

Top management team literatures (Buyl, Boone and Hendriks, 2014; Papadakis and Barwise, 2002) offer a complementary interpretation of the workings of strategists' cognitions and factors which contribute to some "glorious corporate successes as well as some dismal strategic failures" (Schwenk, 1988, p. 41). The cognitive perspective suggests that team members interact through communication, coordination, and other processes and behaviours, and in doing so transform a collection of individual knowledge to team knowledge, resulting in effective team cognition that ultimately guides action.

'Dominant logic', 'shared schema' (Prahalad and Bettis, 1986) or 'collective mind' (Weick and Roberts, 1993) develop as a result of the experiences and social interactions of top managers and are expressed as learned, problem-solving behaviours (Leonard, Beauvais, and Scholl, 2005). 'Cognitive maps' (Tolman, 1948) are interpretive lenses that help decision makers select important aspects of an issue for attention and diagnosis (Schwenk, 1988). In 
this respect, team cognition is a fundamental aspect of 'organisational intelligence' (Bettis and Prahalad, 1995) which provides a set of organisational heuristics that simplify and speedup decision making, allowing the organisation to 'anticipate' its environment. Within the confines of expert decision making (based on domain-specific knowledge, learning and practice) this should not be confused with individual heuristic processing (cognitive 'shortcuts') that lead to errors and biases (Kahneman, Slovic and Tversky, 1982). Intuitive expertise draws on already-stored schemas used in similar situations (Sinclair, 2010) hence speeding-up decision making. Without such schemas, managers and ultimately the organisation would become 'paralysed' by the need to analyse rigorously (Langley, 1995) every ambiguous and uncertain situation.

Consequentially, "building collective intuition that enhances the ability of a top management team to see threats and opportunities sooner and more accurately" (Eisenhardt, 1999, p. 66) is potentially of great value to decision making; it may contribute to faster and more effective responses to triggering events (Eisenhardt, 1989, 1999; Eisenhardt and Martin, 2000), and facilitate collective learning processes (Sadler-Smith, 2008). Collective intuitions are different from group intuitions in that the former presume that the same information is gleaned independently by several group members, whereas the latter refer to individual intuitions of group members related to the same question/problem that can be integrated into a collective insight/solution (Sinclair and Hamilton, 2014).

Expert intuitions have an important influence on the mental models (i.e. patterns or schemas) upon which individuals and groups base their actions (Clarke and Mackaness, 2001; Crossan et al, 1999; Klein, 1997). Theories of collective learning draw on shared mental models built-up from previously learned 'memory objects' (such as declarative knowledge, episodes, and emotions) that are combined to produce situational understandings and are context dependent (Derry, 1996). Mental models are forms of 'patterned thinking'; 
organisational learning theorists contend that the surfacing of mental models through their articulation is necessary to build both shared understanding and acceptance within the organisation (Weick, 1979). Consequently, shared cognition leads to improved team processes and better task performance (e.g. efficiency of communication, accuracy of expectations/predictions, consensus and coordination) (Cannon-Bowers and Salas, 2001), thereby enhancing the team's decision making capabilities.

\section{Method}

In addressing our research question, we used the levels (individual, group, organisation) and processes (Intuiting, Interpreting, Integrating, Institutionalising) of the 4I framework (Crossan et al, 1999) as the basis for our research design and data analysis. This framework offered theoretical and methodological traction in that it allowed us to enquire both into collective intuitions in team settings, and connect this to decision making processes and organisational outcomes (intuitive successes and failures).

\section{Participants}

Research participants were SMT members in three UK police organisations (hereafter referred to as Police Organisation A, B, C). In total there were 23 participants (determined by the size of each SMT: 11, POA; six, POB; six, POC) consisting of senior police officers and senior police staff. Police officer participants included (in descending order of police rank): one Chief Constable, one Deputy Chief Constable, two Assistant Chief Constables, two Chief Superintendents, five Superintendents, five Chief Inspectors and one Special Constable, as well as one Sergeant and one Police Constable (the latter were not members of the respective SMT, but were key players in one of the incidents which formed the basis of the data collection). The police staff included: two Directors of HR, one Business Manager, and one Director of Finance. Participants comprised five females and 18 males. At the time of the 
interviews, the police officers had an average of 19.5 years of experience in policing, ranging from four to 30 years. The police staff had an average of 12.7 years of experience ranging from seven to 25 years in their respective domains (e.g. Finance, HR). As such, our participants were deemed to have relevant and necessary domain expertise.

\section{Data Collection}

Data were collected over a four-month period using a variant of the Critical Incident Technique (CIT) (Chell, 1998; Flanagan, 1954) to capture 'intuitive hits' and 'intuitive misses' (see Akinci, 2014). To the best of our knowledge, CIT has not been used previously to explore a collective phenomenon in the way employed here using focus groups. In total 16 interviews (seven, POA; four, POB; five, POC), corresponding to a total of 14.5 hours, were conducted to gather data relating to two incidents from each organisation. The level of analysis was the group (i.e. SMT): at the initial stage we collected data in semi-structured focus group interviews. The unit of analysis was the decision: we asked each SMT to provide two significant decisions (one 'hit' and one 'miss'; six incidents in total). A list of generic questions was prepared to initiate conversation into team decision making by focusing on each incident (see Appendix). The incidents were relatively recent, and since the interviews were conducted in focus groups, participants' discussions were instrumental in recalling the events. The interview format was in-line with the CIT procedure, that is, we asked about the background (what led up to it?), the course (what happened?), and the result (what was the outcome?) of each incident. Further probing questions were used to scrutinize closely the role of intuition in these processes. In the second stage, we conducted follow-up interviews with smaller groups and/or on an individual basis (based on availability) in order to clarify details from initial focus group interviews. All interviews were digitally recorded and transcribed verbatim. Participant anonymity was guaranteed. 


\section{Data Analysis}

We employed a thematic analysis (King, 2004) which allowed for both inductive and deductive approaches (in this sense our research shares some of the features of 'abduction', see Klag and Langley, 2013). The initial analytical approach was open-ended (Strauss and Corbin, 1990) driven by a broad interest in the various levels and processes as set out in the 4I framework. Interview transcripts were analysed and coded in a three-stage procedure. In the first stage of 'unitising', the first-named author became familiar with the data by reading and re-reading the transcripts to identify individual 'thought units' (Gioia and Sims, 1986). Thought units ranged from a phrase, through a complete sentence, to several sentences and were deployed to capture a complete thought or idea relevant to the research aims.

Once thought units were identified (783 in total), we systematically analysed these to uncover concepts from the interview data in accordance with qualitative procedures (Corbin and Strauss, 2008). Concepts were allowed to emerge from the data through reading, rereading and interpreting the thought units. In the second stage of 'categorising', statements relating to similar categories were grouped into preliminary concepts and assigned descriptive labels (i.e. codes) (Miles and Huberman, 1994). This process continued until we reached a point of saturation and every relevant thought unit was assigned to a concept (Corbin and Strauss, 2008). We identified 25 concepts (sub-processes) in total. These were then interpreted and refined in light of the extant theory (see Klag and Langley, 2013).

In the third stage of 'classifying', the concepts were grouped into eight themes, and two aggregate dimensions of 'feed-forward' and 'feedback' loops. We used the 4I processes as a source of relevant 'sensitizing concepts' (Blumer, 1954; Charmaz, 2003; Heath and Cowley, 2004). We also "looked for information that would disconfirm or add to our initial expectations" (Maznevski and Chudoba, 2000, p. 480). Doing so, we identified additional processes of 'inquiring' and 'internalising' in the feed-forward loop. Furthermore, we 
identified 'reinterpreting' and 'reinternalising' which captured feedback loop processes and were absent in the original 4I framework. Hence, the 4I framework helped to structure the analysis but it did not drive our thinking (see Klag and Langley, 2013). Table 1 reports representative data from this coding.

\section{[TABLE 1 HERE]}

We generated six narrative vignettes of the intuitive hits and misses (summarised in Table 2). In the presentation of the findings below we identify relevant quotes from the interviews relating to our research question.

\section{[TABLE 2 HERE]}

\section{Findings}

We present our analysis of the decision making and organisational learning processes drawing on a range of examples from various incidents, corresponding to the levels of analysis. Selected quotations from interview data are provided, and relevant themes are indicated using italic font. Figure 1 shows our elaboration on the 4I framework based on the empirical findings presented below.

\section{[FIGURE 1 HERE]}

\section{Individual Level: Intuiting and Inquiring}

In line with the view of information processing as a dual-process, 'intuiting' and 'inquiring' (i.e. deliberating) were evident at the outset of the decision making processes. Officers described intuitive knowing as using expertise and gut feeling (System 1). Some used the term 'professional judgement' to refer to intuitive judgements arising from their domain-specific learning, knowledge and experiences in policing consistent with the notion of expertise. For example, in Organisational Restructure participants attributed the success of the restructure to 
their expertise-based intuitions emanating from their knowledge in policing and professional seniority.

"A lot of the intuition side of things was perhaps who you were actually going to put in what positions because you knew that you were choosing to spread the expertise then you had to make some quite painful decisions as to where people actually went. And I think a lot of that was perhaps the gut feeling, knowing the individuals, knowing their strengths, perhaps knowing their weaknesses and then balancing those out to make the team as strong as we possibly could...perhaps your intuition has a part in that and deciding where you place your resources at the end of the day." [Participant I, Organisational Restructure, using expertise]

Intuition also appeared as a gut feeling that felt right or wrong, manifesting as positively- or negatively-valenced affect. This state was evident strongly in the Colour-Matching Event, where emotional responses surfaced as stress and anxiety.

"I was horrified, I was horrified, and I said oh no, and I hit my forehead like you do, and I said that's awful, that's an honest... that was my gut reaction, oh no, we shot ourselves in the foot, when I saw the bit that said about having your colour profiles done... but I immediately spotted that particular thing, and just the way the whole programme was set out, in my view was not appropriate, and I felt embarrassed about it, if I'm honest." [Participant P, Colour-Matching Event, gut feeling]

Furthermore, participants formed judgements by attending to the situation more deliberately through scanning and analysing (System 2). Scanning involved a deliberate search for knowledge from external or internal sources to monitor the environment for information; analysing involved longer and more careful consideration of the situation or information which then fed into and influenced the decision process. Consequently, information from scanning may become a source for further analytical or intuitive processing. In Failed Drugs Bust, the police officer went to the address in question several times to check i.e. scanning whether there was any activity that would corroborate the intelligence; his intuitive judgement (albeit incorrect) was that it looked like a drug dealer's house:

"Yeah, you know, it's not a nice address with the curtains drawn and flowers on the window sill. Yeah, it looks like a drugs address, I'll be happy with that." [Participant K, Failed Drugs Bust, scanning]

Interestingly, in 'intuitive hits' our participants used both intuition and deliberation jointly as 
expressed by this officer: "In reality, we do know our business quite well, and can patch something, we might not get $100 \%$, but it's certainly up around the $80 \%$, and the difficulty we have is analysing that last $20 \%$ really." [Participant E]. In some cases intuition and deliberation occurred simultaneously, whereas in others they were sequential depending on context, available information, and time pressure. For example, in Event Cancellation, the Assistant Chief Constable's initial reaction was a gut feeling; afterwards he went on to gather more information and consult the SMT to back-up his intuition. Conversely in Organisational Restructure, the SMT first brought in a consultancy firm to examine the organisation's policing needs and design a restructuring formula (i.e. analysing); failure of this analytic approach led to a realisation that their expert intuitions were needed to formulate the allocation of resources.

"When the [consultancy firm] came to us they were there just at the point of all these discussions and they were asking us, "So what are your business rules in terms of how you redistribute staff, and what is your rationale in terms of deploying $\mathrm{X}$ and $\mathrm{Y}$ and how have you decided that you can take from there and add to here for instance?" [analysing] and I think that's really where you see the intuitive management. There is no magic equation, there is no magic formula and it's relying upon experience and the understanding, finger in the air, but perhaps more professional judgement of what's needed to deliver policing in [.....]." [Participant C, Organisational Restructure, using expertise]

On the other hand, the 'intuitive misses' revealed decision making to follow a more confused and convoluted trajectory; there appeared to be lack of deliberating in all three cases. Only in Failed Drugs Bust did some analysing take place when the intelligence unit gathered and corroborated information prior to the drug search, however it later transpired after the operation failed that the information was inadequate and inaccurate. In other two 'intuitive misses' (i.e. Colour-Matching Event and Staff Relocation) deliberating was not observed, and acting on uninformed intuition led to undesirable outcomes. 
Individual to Group Level: Interpreting Intuitions

Interpretation of intuitions involved communication and conversational processes. It was also the means by which the participants made sense of and reasoned about their intuitions. In attempting to articulate intuitive judgements, participants engaged in dialogue (verbalising), with the intention to express mental images (visualising) and refine intuitions linguistically (rationalising). Sometimes participants made sense of their intuitions through an internal conversational process, i.e. in the sense of 'talking to one's self' (e.g. conscious thinking, contemplating and articulating):

"Where I was coming from initially is that I'm looking out from this, and saying what is the view from outside, so I think in terms of the policing context... our decisions are looking at what's the impact going to be, particularly in, what they say a single top down target of public confidence and improved public confidence, so for me that was the big look." [Participant N, Event Cancellation, verbalising]

However, there were situations where ideas were not consciously and explicitly developed, because the officers lacked the vocabulary to explain fully their rationales. In the absence of words, visualising (System 1) enabled expression and interpretation, and thereby facilitated a productive dialogue:

"So we had all this scribble on the board like that and around that and then what I had to do was I had to understand of a) what the organisation wanted and b) what we could deliver in my small area of [.....] and take that and deliver the picture into some sort of reality and that's where the process is started." [Participant V, Neighbourhood Policing, visualising]

It is unsurprising that intuitive judgements were rationalised and reasoned logically to render them intelligible and acceptable to others, especially given the strictures of the legal frameworks within which police organisations operate:

"Your intuition may be the starting point but then you are going to have to rationalise it, you are going to have to research it, you are going to have to be able to evidence it, or if you're not going to be able to take other people with you you're not actually going to be able to get support for it." [Participant U, Neighbourhood Policing, rationalising] 
Verbalising and rationalising (System 2) through contemplating, articulating and interpreting intuitions played a significant role in sensemaking and communicating intuitive judgements both to one's self and to others.

\section{Group Level: Integrating Collective Intuitions in Team Decision Processes}

Collective intuitions figured prominently in group level decision making, and were relayed to us by participants as instances where they arrived independently at the same intuitive judgement as their colleagues when confronted jointly by a given problem. These were then captured and shared in SMT meetings as a source of articulable knowledge and information. Collective intuitions surfaced when senior decision makers sought the team's judgement to gain a wider perspective, and to confirm or refute the credibility of their personal intuitions. Doing so, they utilised their collective expertise in the policing domain. Collectively, intuitions became explicit and were validated via the various processes outlined below.

Decision makers often obtained advice and expert knowledge through consulting and validating (System 2) from the organisation's experienced and trusted officers and managers. Wider implications of these findings suggest that intuitions that are consulted upon and confirmed within the SMT catalyse shared understanding, decision making and action. In Event Cancellation, senior officers addressed the issue collectively and confirmed their individual intuitions with members of the team with relevant expertise. By seeking each other's expert opinions their collective intuition was that the event ought to be cancelled.

"[Richard] brought it to my attention, I brought in the Finance Director as well, there's a whole indicator, two levels of a view, what's his sort of conscious tell him financially, and I think between the three of us, intuitively, in quick time, we said "this can't happen". [Participant L, Event Cancellation, consulting]

"Effectively Richard presented to me the issue in a, I think, correct, judgemental way, I mean you'd got a judgement in your mind. And I think I would say Richard was coming to me to confirm, endorse, rubber-stamp that decision, but I suppose I'd got an option, I could have said no I think it's alright, let it happen." [Participant L, Event Cancellation, validating] 
We identified further group level sub-processes that enabled and facilitated the coherent integration of collective intuitions in the organisation's decision making processes. These involved deliberative processes of generating options, negotiating and influencing (System 2) where analytical brainstorming processes were necessary to generate, evaluate and choose from a range of alternatives:

"Well... we actually, I think we talked about every Sergeant who was on the division, didn't we, as to who might be suitable, how it might work, I mean, we were actually looking at whether there was any ability to bring a third Sergeant... but we had to consider budgetary implications, and that kind of ruled it out... and then we considered bringing another Constable in to assist with the kind of management of the area, and that's the route we've actually gone down." [Participant W, Staff Relocation, generating options]

"Because each of us had different demands, and it was just trying to reconcile those different demands, not just based on say numbers and input in terms of demand, and then 'okay, so that means you need that amount of people, because we're going to cover this many shifts, and this many hours'..." [Participant D, Organisational Restructure, negotiating]

"At the time they were persuaded by my kind of contrary argument really... but... they understood the motivation being a right motivation once we talked about it... So I explained why it was important, that it wasn't just about frippery, it was really, it was about presentation and confidence, and they said, oh right'o, and they got it, they understood where I was coming from, and they said, in that case, fine..." [Participant O, Colour-Matching Event, influencing]

Disagreement and conflict amongst the team members was not uncommon, however building consensus also played a significant role in developing shared understanding and collaborating (System 2 processes) so as to be able to take action (see Table 1).

\section{Group to Organisation Level: Internalising Team Learning}

Individual and group learning was not always established formally and explicitly within the organisation's systems, structures and procedures. In three cases (Event Cancellation; Failed Drugs Bust; Colour-Matching Event) although no formalised procedures were developed as a result of these learning experiences, a form of non-formal learning (involving both System 1 and System 2) became internalised within the organisation through the implicit and explicit knowledge, experience and understanding of the situation. For example, in referring to the 
failed operation in Failed Drugs Bust - despite the incident's serious repercussions - two senior officers reported:

"No, I wouldn't say we've sort of reformulated the way we do our business, no we haven't... Is virtually everyone within the BCU aware of this incident, yes they are... So it becomes a common sense point, which if you're going to execute a warrant, you need to actually make sure that it's current." [Participant F, Failed Drugs Bust, non-formal learning]

"Errors such as that are important in that we need to learn from them ...thankfully this is one of those once in a blue moon events, as opposed to something, if it happened all the time I would be really, really anxious, and we would be putting in place more stringent checks and balances before people went out executing warrants." [Participant A, Failed Drugs Bust, non-formal learning]

For shared understanding to develop within the wider group and the organisation, officers indicated the importance of communicating the decision makers' objectives and plans further down the hierarchy and involving (System 2 processes) the 'grassroots' to participate in decision making so as to prepare for smooth, coherent and concerted action. Furthermore, teams engaged in various other processes, modelling through their own actions, in order to instil a sense and purpose of what the police organisation stands for. The SMT's values and ethos were an implicit influence on internalising decisions, and articulated a moral code and professional standards of behaviour. More specifically, these involved: safeguarding reputation of the organisation in public eye in order to maintain and restore trust in the police, and adhering to values to do what is right; as well as being accountable for when things go wrong, but also maintaining credibility of the people involved by empowering them as a way of positive reinforcement (see Table 1).

\section{Organisation Level: Institutionalising Organisational Learning}

Institutionalising as a type of formal learning was evident in other three incidents concerned with organisational issues rather than operational matters, namely: Organisational Restructure (implementation of new structure to improve efficiency and performance); Neighbourhood Policing (establishment of the neighbourhood teams as a new model of community 
engagement); Staff Relocation (development of the Talent Management Scheme as a result of the SMT's failed attempts to relocate a number of underperforming Sergeants). Two subprocesses were involved, systematising and adjusting (System 2), signifying the importance of deliberative processes in embedding individual and group learning in organisations:

"One of the things that we've done is... the process which we're calling 'Talent Management Scheme'... whereby we have got individuals that actually want to be developed, and to take on new roles within the organisation, so my expectation will be that, when I ask somebody if they'll do it, they'll actually say yes." [Participant W, Staff Relocation, systematising]

"New demands come in, new analysis, new issues arise, so for instance, in Peter's world we've got to re-adjust and lose some capacity which we had in some proactive teams to support the custody, and just supply in a 24-hour basis support to the rest of the BCU wasn't possible under the regime, so there has been some refinement around that." [Participant D, Organisational Restructure, adjusting]

Learning is systematised by being embedded into the organisation's systems and establishing formal mechanisms. In some situations systematised learning was adjusted as an ongoing process as the context of the focal decision changed, and procedures were adapted to fit the current environment in light of new knowledge and the learnings which occurred as a result of having gone through the processes outlined above.

Feedback loop across levels: Reinterpreting and Reinternalising Collective Learning

In the feedback loop, interpreting and internalising manifested as recursive processes across individual, group and organisation levels as an interactive process between cognition and action. Moving between group and individual levels, reinterpreting allowed senior officers to reconsider and refine their individually- and collectively-constructed intuitive judgements and assumptions through conversations. Moving between organisation and group levels, reinternalising presented collective learning opportunities for the SMTs as a result of their shared experiences of organisational success and failure, and informed their ongoing decision making. We illustrate the feedback loop learning as relayed to us in the Colour-Matching Event: 
"I mean it was a lesson, it was a lesson for me. And Karen and I have talked about it, her view is that she should have been more forceful with her view, because they were convinced by me, and actually she said "I still felt it was wrong", and to come forward and say so really." [Participant O, Colour-Matching Event, reinterpreting]

“... like the Black Police Association, the Christian Police Association, all the different groupings that represent different minorities and diverse groups... when they're doing things in the name of [POB], then we need to just check in and Karen put a system in place, about why we check in with what they're doing and make sure it sits with our values, and is seen to sit with our values." [Participant O, Colour-Matching Event, reinternalising]

In this incident, the subsequent collective learning was that the senior officers should have consulted a wider view: "We would have had this conversation to the press, we would have probably spoken to the Police Federation, perhaps Unison to say what's your feeling on this, we'd have tested the water in a proper way, rather than just the few of us round the table... we could do it quickly... just test that water, and use other stakeholders' views in terms of making a decision" [Participant O]. Doing so, they could have made a better informed decision and would have saved the SMT from a big media and public furore.

\section{Discussion of Findings and Implications}

We discuss our findings and their implications in terms of our three main theoretical contributions; we further propose practical suggestions by which expert intuitions can be developed collectively to improve decision making and organisational learning.

\section{Interaction of Intuition and Deliberation in Group Settings}

Intuition research in general has overlooked the importance of the interactions between intuitive and deliberative processing, focusing understandably on the former at the expense of the latter, moreover where such interactions have been considered (mostly theoretical) they have tended to be at the individual level (e.g. Louis and Sutton, 1991; Hodgkinson and Clarke, 2007). In exploring the interplay of intuition and deliberation at individual, group and organisation levels, our findings contribute to the links between dual-process theories 
(Epstein, 1994; Evans, 2003, 2008) and organisational learning theory, specifically the 4I framework (Crossan et al, 1999), with the additional process of 'inquiring' (i.e. deliberating, labelled as such in keeping with Crossan et al's 'i' alliteration). These findings reveal that intuition and deliberation function interactively in group decisions and that organisational learning is initiated and facilitated through the joint actions of the two systems. This highlights a limitation in the 4I framework (Crossan et al, 1999) which explicitly acknowledges intuiting but does not consider the role of deliberating and the Type 1/Type 2 duality of information processing within and across levels. Relatedly, the 4I framework indicates a 'feedback loop' learning but falls short of identifying such processes explicitly. In this respect, our findings point to a continuous refinement of the collectively formed intuitions and deliberative reasoning through the process of 'reinterpreting' recurring between the individual and group levels.

Implication 1: The interaction of intuition and deliberation has implications for improved group decision making. In our police incidents, all three 'intuitive hits' showed joint operation of intuitive and deliberative processing, whereas in 'intuitive misses' inquiring was absent. Our evidence indicates that while lack of deliberation may have negative consequences, intuition should also be used with caution. We witnessed a significant consequence of this in the case of Failed Drugs Bust which resulted not only in a decision making error but also in significant reputational damage: officers made a biased (and ultimately incorrect judgement) based on the appearance of the house. It has been long-known that the operations of associative memory (System 1) contribute to confirmation bias in that people seek data that are likely to be compatible with the beliefs they currently hold, in this case about the criminality of the persons occupying certain types of dwelling (see Gilovich, Griffin and Kahneman, 2002). As a result, biased judgement combined with the lack of thorough inquiry (i.e. deliberation) led to the officer's gut feelings failing both him and the organisation 
severely. Our findings in the policing domain are in line with the view that effective decision making involves use of informed intuition alongside robust analysis (Dörfler and Ackermann, 2012). Additionally, 'reinterpreting' cognitive maps and deliberate interventions in intuition (see Evans and Stanovich, 2013) help develop expert intuitions (Salas et al, 2010), improves the quality of intuitive decision making and contributes to organisational learning. Paraphrasing Wenger (1998), we have found that in communities of practice where learning is to the fore, intuition and deliberation "imply each other, they do not substitute for each other" (p. 67). This finding provides a link between the communities of practice literature and the organisational learning literature and has significant practical implications.

\section{Internalising Team Learning}

Our research further elaborates the 4I framework with the inclusion of 'internalising' and 'reinternalising' (in the feedback loop) processes which are operative as learning moves from the group to organisation level (and vice versa). The process of internalising links team processes with perceived norms, values, codes of professional conduct and issue construction within the community of practice (Sonenshein, 2007; Wenger, 1998). While institutionalising is conceptualised as 'nonhuman elements' of organisational learning (see Crossan et al, 1999), we found that internalising resides tacitly in the collective ethos and identity manifested in the practices of the professional community of senior police officers. As such, internalising captured learning through collective practice and co-experience, but fell short of being formally established in the procedures of the organisational systems. Reinternalising reinforced the collective learning in an iterative manner.

Implication 2: Effective 'internalising' and 'reinternalising' are crucial for enabling and strengthening organisational learning. Lack of institutionalising (i.e. learning that does not proceed beyond 'integrating') has negative implications for organisational learning in that in failing to develop the requisite systems and structures, organisations risk repeating previous 
mistakes and may fail to capitalise on the power of intuitive thinking (Salas et al, 2010). Through 'internalising' it is possible to support learning, for example by establishing the master-apprentice relationship (Prietula and Simon, 1989) in which tacit knowledge can be passed on and intuiting can develop. Our research extends the 'learning from mistakes' literature (Tjosvold, Yu and Hui, 2004) in that we found that 'internalising' promotes group learning from intuitive mistakes. In this regard, people may learn from direct experience and the experiences of others (Levitt and March, 1988), such learning can be made accessible for reuse (exploitation), and to influence future behaviours and actions (exploration) (Crossan et al, 1999; March, 1991).

We observed internalising in one 'intuitive hit' (Event Cancellation), and two 'intuitive misses' (Failed Drugs Bust; Colour-Matching Event); and institutionalising in two 'intuitive hits' (Organisational Restructure; Neighbourhood Policing) and one 'intuitive miss' (Staff Relocation). Internalising occurred in incidents involving primarily operational matters, and institutionalising occurred in organisational matters. Our findings suggest that learning becomes internalised within the decision making group through direct experience; as such internalising represents implicit learning that is embodied in the group that executes the procedures (e.g. search warrants or chief officer group). Wider organisational learning is also possible by informally sharing of experiences (e.g. on the 'grapevine'). On the other hand, managerial/organisational decisions, that are applicable to the entire organisation, are more likely to be established in the systems of the organisation through institutionalising (e.g. new talent management scheme). We deduce that firstly, formal transformation of experience into routines involves costs, and secondly organisations (e.g. police forces) that deal with complexity, uncertainty and ambiguous information are more sensitized to the interpretation of dynamic situations than those in stable environments. Therefore-at least in the police operational context - not everything can be recorded in formal rules as such organisations 
often have to, and we argue do so legitimately, rely on the intuitions of their experienced officers. The power of internalising and reinternalising lies in the fact that the implications of experience can be transferred from those who experienced it to those who did not.

\section{Developing Collective Intuitions}

Collective intuitions are powerful, difficult-to-imitate and valuable cognitive resources (cf. Barney, 1991) as relayed to us in decision making processes within the senior teams. Participants drew advice and experiences from other people (i.e. experts) to validate their own intuitive judgement, rather than from sources of explicit information. In light of our findings, we conceptualise collective intuition as 'independently formed judgement based on domainspecific knowledge, experience and cognitive ability; shared and interpreted collectively'. In this respect, we observed that collective reflecting and sensemaking was imperative for building shared meaning and understanding (Weick, 1995, 2001) integral to the development of collective intuitions. Our conceptualisation of collective intuition extends the sensemaking and intuition literature, which as noted has tended to focus on issue construction and intuitive judgement principally at the individual level (Sonenshein, 2007, p. 1029), into the organisational domain. Our research sheds light on the collective factors which inform how groups of individuals under conditions of equivocality and uncertainty construct interpretations and arrive at a course of action. For example, in organisational settings the role of experience in these processes must be conceptualised not merely as an individual level phenomenon but collectively as well.

Implication 3: Collective sharing and reflecting on intuitive experiences have implications for learning from past incidents (including mistakes) and developing collective intuitions to improve future decision making. A key issue in organisational learning is capturing meaning that is experienced collectively, across the organisation, beyond individual insights (Sillence and Shipton, 2013). As such, lessons learned from previous experiences have to be translated 
and used to make sense of new situations (Elliott and Macpherson, 2010). 'Reinterpreting' and 'reinternalising' in particular can be instrumental in reinforcing collective decision making and learning processes. Police work is an experientially-based occupation and "what individuals learn always and inevitably reflect the social context in which they learn it and in which they put it into practice" (Brown and Duguid, 2001, p. 201). For example, police teams work and learn collaboratively, and most police officers are socialised successfully to actions and beliefs recognisable as acceptable police behaviour (Van Maanen, 1973). 'Thinking together' (Pyrko, Dörfler and Eden, 2016) facilitates the social formation of knowledge in these communities of practice (Wenger, 1998) rather than its mere acquisition. Within these interpretive sensemaking communities (Daft and Weick, 1984) a 'kind' as opposed to 'wicked' learning environment (Hogarth, 2001, 2010) is a necessary condition for the development of collective intuitions through relevant, accurate, and timely feedback (Kahneman and Klein, 2009).

The incident of 'Colour-Matching' reiterates the importance of sharing individual intuitions (i.e. how 'knowledge generated by the individual [intuitively] does not come to bear on the organisation independently', Crossan et al, 1999, p. 524) and the significance of social factors in intuitive judgement. Certain group members were able to make stronger justifications (albeit on 'wrong' gut feeling), and doing so influenced the team, for example via 'social pressure' (Sonenshein, 2007, p. 1028), to follow their lead. In such circumstances, some decision makers with less social influence may fail to attend to or subconsciously suppress intuitions (see: Dane, 2011). It is our contention, based on these findings, that suppression of intuitions and their interpretation may hinder development of collective intuitions and produce organisational learning conditions that are conducive to the development of poor collective decision making leading, for example, to hubristic leadership (Claxton, Owen and Sadler-Smith, 2014). 


\section{Conclusion}

Our research, which is exploratory, whilst seeking to lay the groundwork for future studies of collective intuition and organisational learning, is subject to a number of limitations. For example, the research design relied on retrospective recollections of the participants and the research approach was interpretive. Future studies of collective intuition could utilise direct observation methods by attending team meetings where decisions are discussed and taken collectively. Moreover, the generalisability of our findings to other police forces in different locales and to other sectors where similar collective decision making processes are operative warrants further investigation. The implications of our findings go beyond the policing domain and open-up areas for future research on intuition and organisational learning more widely. Future research could therefore explore how experts in different occupational and institutional contexts develop and accomplish collective intuitions in team settings.

By casting new light on collective decision making and organisational learning processes in senior management teams in police organisations, our research has made several unique contributions to theories of intuition and organisational learning. We have helped move intuition research forward from an almost exclusive reliance on the individual level of analysis to the study of intuition at the collective level, and highlighted the importance of the interplay of intuition and deliberation in group decisions. We also offer an empiricallyderived elaboration of the highly influential 4I framework and forge links between this model (in which intuition is elemental), the wider organisational learning and knowledge literatures and dual-process formulations of intuition. In doing so, we have not only bridged a variety of relevant but previously unconnected literatures via our focal concept of collective intuition, but also provided a foundation for future studies of this vitally important but under-researched organisational phenomenon. 


\section{References}

Agor, W. H. (1986). 'The logic of intuition: how top executives make important decisions', Organizational Dynamics, 14, pp. 5-18.

Akinci, C. (2014). 'Capturing intuitions in decision making: a case for the critical incident technique'. In M. Sinclair (ed), Handbook of Research Methods on Intuition, pp. 147-159. Cheltenham, UK: Edward Elgar.

Akinci, C. and E. Sadler-Smith (2012). 'Intuition in management research: a historical review', International Journal of Management Reviews, 14, pp. 104-122.

Barney, J. (1991). 'Firm resources and sustained competitive advantage', Journal of Management, 17, pp. 99-120.

Bettis, R. A. and C. K. Prahalad (1995). 'The dominant logic: retrospective and extension', Strategic Management Journal, 16, pp. 5-14.

Blumer, H. (1954). 'What is wrong with social theory?', American Sociological Review, 18, pp. 3-10.

Brown, J. S. and P. Duguid (1991). 'Organizational learning and communities-of-practice: Toward a unified view of working, learning and innovation', Organization Science, 2, pp. 40-57.

Brown, J. S. and P. Duguid (2001). 'Knowledge and organization: A social-practice perspective', Organization Science, 12, pp. 198-213.

Buyl, T., C. Boone and W. Hendriks (2014). 'Top management team members' decision influence and cooperative behaviour: an empirical study in the information technology industry', British Journal of Management, 25, pp. 285-304.

Cannon-Bowers, J. A. and E. Salas (2001). 'Reflections on shared cognition", Journal of Organizational Behavior, 22, pp. 195-202.

Charmaz, K. (2003). 'Grounded theory: objectivist and constructivist methods'. In N. K. Denzin and Y. S. Lincoln (eds), Strategies for Qualitative Inquiry, $2^{\text {nd }}$ ed, pp. 249-291. Thousand Oaks, CA: SAGE.

Chell, E. (1998). 'Critical incident technique'. In G. Symon and C. Cassell (eds), Qualitative Methods and Analysis in Organizational Research: A Practical Guide. London: SAGE.

Clarke, I. and W. Mackaness (2001). 'Management 'intuition': an interpretative account of structure and content of decision schemas using cognitive maps', Journal of Management Studies, 38, pp. 147-172. 
Claxton, G., D. Owen and E. Sadler-Smith (2014). 'Hubris in leadership: A peril of unbridled intuition?, Leadership, 11, pp. 57-78.

Cohen, M. D., J. G. March and J. P. Olsen (1972). 'A garbage can model of organizational choice', Administrative Science Quarterly, 17, pp. 1-25.

Corbin, J. and A. Strauss (2008). Basics of Qualitative Research. Los Angeles: SAGE.

Crossan, M. M., H. W. Lane and R. E. White (1999). 'An organizational learning framework: from intuition to institution', Academy of Management Review, 24, pp. 522-537.

Daft, R. L. and K. E. Weick (1984). 'Toward a model of organizations as interpretation systems', Academy of Management Review, 9, pp. 284-295.

Dane, E. (2011). 'Capturing intuitions 'in flight': Observations from research on attention and mindfulness', in M. Sinclair (ed) Handbook of Intuition Research, pp. 217-226. Cheltenham: Edward Elgar.

Dane, E. and M. G. Pratt (2007). 'Exploring intuition and its role in managerial decision making', Academy of Management Review, 32, pp. 33-54.

Derry, S. (1996). 'Cognitive schema theory in the constructivist debate', Educational Psychologist, 31, pp. 163-174.

Dörfler, V. and F. Ackermann (2012). 'Understanding intuition: the case for two forms of intuition', Management Learning, 43, pp. 545-564.

Dreyfus, S. E. (2014). 'System 0: The overlooked explanation of expert intuition', in M. Sinclair (ed), Handbook of Research Methods on Intuition, pp. 15-27. Cheltenham: Edward Elgar.

Easterby-Smith, M. (1997). 'Disciplines of organizational learning: contributions and critiques', Human Relations, 50, pp. 1085-1113.

Eisenhardt, K. M. (1989). 'Making fast strategic decisions in high-velocity environments', Academy of Management Journal, 32, pp. 543-576.

Eisenhardt, K. M. (1999). 'Strategy as strategic decision making', Sloan Management Review, Spring, pp. 65-72.

Eisenhardt, K. M. and J. Martin (2000). 'Dynamic capabilities: what are they?', Strategic Management Journal, 21, pp. 1105-1121.

Elliott, D. and A. Macpherson (2010) 'Policy and practice: Recursive learning from crisis', Group \& Organization Management, 35, pp. 572-605.

Epstein, S. (1994). 'Integration of the cognitive and the psychodynamic unconscious', American Psychologist, 49, pp. 709-724. 
Epstein, S., R. Pacini, V. Denes-Raj and H. Heier (1996). 'Individual differences in intuitiveexperiential and analytical-rational thinking styles', Journal of Personality and Social Psychology, 71, pp. 390-405.

Evans, J. St. B. T. (2003). 'In two minds: dual-process accounts of reasoning', Trends in Cognitive Sciences, 7, pp. 454-459.

Evans, J. St. B. T. (2008). 'Dual-processing accounts of reasoning, judgment, and social cognition', Annual Review of Psychology, 59, pp. 255-278.

Evans, J. St. B. T. and K. E. Stanovich (2013). 'Dual-process theories of higher cognition advancing the debate', Perspectives on Psychological Science, 8, pp. 223-241.

Flanagan, J. C. (1954). 'The critical incident technique', Psychological Bulletin, 51, pp. $327-$ 358.

Gherardi, S. and D. Nicolini (2001). 'The sociological foundations of organizational learning', in Dierkes, M., Berthoin Antal, A., Child, J. and Nonaka, I. (Eds.) Handbook of Organizational Learning and Knowledge, New York: Oxford University Press.

Gilovich, T., D. Griffin and D. Kahneman (eds), (2002). Heuristics and biases: The psychology of intuitive judgment. Cambridge: Cambridge University Press.

Gioia, D. A. and H. P. Sims (1986). 'Cognition-behavior connections: attribution and verbal behavior in leader-subordinate interactions', Organizational Behavior and Human Decision Processes, 37, pp. 197-229.

Hayes, J. and C. W. Allinson (1994). 'Cognitive style and its relevance for management practice', British Journal of Management, 5, pp. 53-71.

Heath, H. and S. Cowley (2004). 'Developing a grounded theory approach: a comparison of Glaser and Strauss', International Journal of Nursing Studies, 41, pp. 141-150.

Hodgkinson, G. P. and I. Clarke (2007). 'Exploring the cognitive significance of organizational strategizing: A dual-process framework and research agenda', Human Relations, 60, pp. 243-255.

Hogarth, R. M. (2001). Educating Intuition. Chicago: The University of Chicago Press.

Hogarth, R. M. (2010). 'Intuition: a challenge for psychological research on decision making', Psychological Inquiry, 21, pp. 338-353.

Kahneman, D. and G. Klein (2009). 'Conditions for intuitive expertise: a failure to disagree', The American Psychologist, 64, pp. 515-526.

Kahneman, D., P. Slovic, and A. Tversky (eds) (1982). Judgment Under Uncertainty: Heuristics and Biases, New York: Cambridge University Press. 
King, N. (2004). 'Using templates in the thematic analysis of text'. In C. Cassell and G. Symon (eds), Essential Guide To Qualitative Methods In Organizational Research, pp. 256-270. London: SAGE.

Klag, M. and A. Langley (2013). 'Approaching the conceptual leap in qualitative research', International Journal of Management Reviews, 15, pp. 149-166.

Klein, G. (1997). 'Developing expertise in decision making', Thinking and Reasoning, 3, pp. 337-352.

Langley, A. (1995). 'Between 'paralysis by analysis' and 'extinction by instinct', Sloan Management Review, 36, pp. 63-76.

Lave, J. and E. Wenger (1991). Situated Learning: Legitimate Peripheral Participation. Cambridge: Cambridge University Press.

Leonard, N. H., L. L. Beauvais and R. W. Scholl (2005). 'A multi-level model of group cognitive style in strategic decision making', Journal of Managerial Issues, 17, pp. 119138.

Levitt, B. and J. March (1988). 'Organizational learning', Annual Review of Sociology, 14, pp. 319-340.

Lieberman, M. D. (2007). 'Social cognitive neuroscience: A review of core processes', Annual Review of Psychology, 58, pp. 259-289.

Louis, M. R. and R. I. Sutton (1991). 'Switching cognitive gears: From habits of mind to active thinking', Human Relations, 44, pp. 55-76.

March, J. G. (1991). 'Exploration and exploitation in organizational learning', Organization Science, 2, pp. 71-87.

Maznevski, M. L. and K. M. Chudoba (2000). 'Bridging space over time: global virtual team dynamics and effectiveness', Organization Science, 11, pp. 473-492.

Miles, M. B. and A. M. Huberman (1994). An Expanded Sourcebook: Qualitative Data Analysis, $2^{\text {nd }}$ ed. Thousand Oaks: SAGE.

Miller, C. C. and R. D. Ireland (2005). 'Intuition in strategic decision making: friend or foe in the fast-paced 21st century?', Academy of Management Executive, 19, pp. 19-30.

Nickols, Fred W. (2000). 'The knowledge in knowledge management', Cortada, James W. \& Woods, John A. (eds). The Knowledge Management Yearbook 2000-2001, ButterworthHeinemann, Boston, MA, 12-21.

Nonaka, I. (1994). 'A dynamic theory of organizational knowledge creation', Organization Science, 5, pp. 14-37. 
Nonaka, I. and H. Takeuchi (1995). The Knowledge-Creating Company: How Japanese Companies Create the Dynamics of Innovation, New York: Oxford University Press.

Nonaka, I., R. Toyama and N. Konno (2000). 'SECI, Ba and leadership: A unified model of dynamic knowledge creation', Long Range Planning, 33, pp. 5-34.

Nonaka, I., and G. Von Krogh (2009). 'Perspective-Tacit knowledge and knowledge conversion: Controversy and advancement in organizational knowledge creation theory', Organization Science, 20(3), pp. 635-652.

Papadakis, V. M. and P. Barwise (2002). 'How much do CEOs and top managers matter in strategic decision-making?', British Journal of Management, 13, pp. 83-95.

Polanyi, M. (1962a). Personal Knowledge: Towards a Post-Critical Philosophy, Routledge, London, UK.

Polanyi, M. (1962b). 'Tacit knowing: Its bearing on some problems of philosophy', Reviews of Modern Physics, 34(4), pp. 601-616.

Polanyi, M. (1966) The Tacit Dimension. Garden City, NY: Anchor Books.

Prahalad, C. K. and R. A. Bettis (1986). 'The dominant logic: a new linkage between diversity and performance', Strategic Management Journal, 7, pp. 485-501.

Prietula, J. M. and H. A. Simon (1989). 'The experts in your midst', Harvard Business Review, 67, pp. 120-124.

Pyrko, I., V. Dörfler and C. Eden (2016) 'Thinking together: What makes communities of practice work?', Human Relations, 70, pp. 389-409.

Russell, B. A. (1948) Human Knowledge: Its Scope and Limits, Routledge, London, UK.

Sadler-Smith, E. (2008). 'The role of intuition in collective learning and the development of shared meaning', Advances in Developing Human Resources, 10, pp. 494-508.

Sadler-Smith, E. and E. Shefy (2004). 'The intuitive executive: understanding and applying 'gut feel' in decision-making', Academy of Management Executive, 18, pp. 76-91.

Salas. E., M. A. Rosen and D. DiazGranados (2010). 'Expertise-based intuition and decision making in organizations', Journal of Management, 36, pp. 941-973.

Schwenk, C. R. (1988). 'The cognitive perspective on strategic decision making', Journal of Management Studies, 25, pp. 41-55.

Sillence, J. and H. Shipton (2013). 'More than a cognitive experience: Unfamiliarity, invalidation, and emotion in organizational learning', Journal of Management Inquiry, 22(3), pp. 342-355.

Simon, H. A. (1955). 'A behavioural model of rational choice', Quarterly Journal of Economics, 69, pp. 99-118. 
Simon, H. A. (1987). 'Making management decisions: the role of intuition and emotion', Academy of Management Executive, 1, pp. 57-64.

Simon, H. A. (1992). 'What is an "explanation" of behaviour?', American Psychological Society, 3, pp. 150-161.

Sinclair. M. (2010). 'Misconceptions about intuition', Psychological Inquiry, 21, pp. 378-386.

Sinclair, M., N. M. Ashkanasy, P. Chattopadhyay and M. V. Boyle (2002). 'Determinants of intuitive decision making in management: The moderating role of affect', in N. M. Ashkanasy, W. Zerbe and C. E. J. Hartel (eds), Managing Emotions in the Workplace, pp. 143-163. Armonk, NY: M.E. Sharpe.

Sinclair. M. and A. Hamilton (2014). 'Mapping group intuitions' in M. Sinclair (ed), Handbook of Research Methods on Intuition, pp. 199-216. Cheltenham: Edward Elgar.

Sonenshein, S. (2007). 'The role of construction, intuition, and justification in responding to ethical issues at work: The sensemaking-intuition model', Academy of Management Review, 32(4), pp. 1022-1040.

Stanovich, K. E. and R. F. West (2000). 'Individual differences in reasoning: implications for the rationality debate?', Behavioural and Brain Sciences, 23, pp. 643-726.

Strauss, A. and J. Corbin (1990). Basics of Qualitative Research: Grounded Theory Procedures and Techniques. Newbury Park, CA: SAGE.

Tjosvold, D., Z.Y. Yu, and C. Hui (2004). 'Team learning from mistakes: the contribution of cooperative goals and problem-solving', Journal of Management Studies, 41(7), pp. 12231245.

Tolman, E. (1948). 'Cognitive maps in rats and men', Psychological Review, 1, pp. 189-208.

Tsoukas, H. (2001). 'Where does new organizational knowledge come from?' Keynote address at the International Conference Managing Knowledge: Conversations and Critiques, Leicester University, April 10-11.

Tsoukas, H. (2003) 'Do we really understand tacitness?' in Easterby-Smith, M. and Lyles, M.A. (Eds.) The Blackwell Handbook of Organizational Learning and Knowledge Management, Oxford: Blackwell Publishing.

Van der Heijden, B. I. J. M. (2000). 'The development and psychometric evaluation of a multi-dimensional measurement instrument of professional expertise', High Ability Studies. The Journal of the European Council for High Ability, 11, pp. 9-39.

Van Maanen, J. (1973). 'Observations on the making of policemen', Human Organization, 32, pp. 407-18. 
Vera, D. and M. Crossan (2005). 'Organizational learning and knowledge management: Toward an integrative framework' in Easterby-Smith, M. and Lyles, M. A. (Eds.) The Blackwell Handbook of Organizational Learning and Knowledge Management, Malden: Blackwell Publishing.

Weick, K. E. (1979). The Social Psychology of Organizing. 2nd ed. Reading, MA: AddisonWesley.

Weick, K. E. (1993). 'The collapse of sensemaking in organizations: The Mann Gulch Disaster', Administrative Science Quarterly, 38, pp. 628-652.

Weick, K. E. (1995). Sensemaking in Organizations. Thousand Oaks, CA: SAGE.

Weick, K. E. (2001). Making Sense of the Organization. Malden: Blackwell.

Weick, K. E. and K. H. Roberts (1993). 'Collective mind in organizations: heedful interrelating on flight decks', Administrative Science Quarterly, 38, pp. 357-381.

Weick, K. E., K. M. Sutcliffe and D. Obstfeld (2005). 'Organizing and the process of sensemaking', Organization Science, 16, pp. 409-421.

Wenger, E. (1998). Communities of Practice: Learning, Meaning and Identity. New York: Oxford University Press. 
Table 1: Processes, sub-processes, and representative data

\begin{tabular}{lll}
\hline $\begin{array}{l}\text { Processes } \\
\text { (Themes) }\end{array}$ & $\begin{array}{l}\text { Sub-processes } \\
\text { (Concepts) }\end{array}$ & $\begin{array}{l}\text { Representative data } \\
\text { (Thought units) }\end{array}$ \\
\hline Aggregate dimension: Feed-forward loop \\
\hline Intuiting & Using expertise & $\begin{array}{l}\text { Inevitably we are a product of our learning and our experiences through } \\
\text { the police service, the routes we have taken to the position we're in now, } \\
\text { and the positions, the other various roles we've had will affect those } \\
\text { opinions. [Participant F, Organisational Restructure] }\end{array}$ \\
& $\begin{array}{l}\text { I think it's about emotional decision. I mean, mine was, I didn't actually } \\
\text { give it a lot of thought around that one, did it feel right, yeah it felt } \\
\text { right... it felt like we were at the right place at the right time. [Participant } \\
\text { V, Neighbourhood Policing] }\end{array}$ \\
\hline
\end{tabular}

Inquiring Scanning People had gone, we'd been sending people up, we didn't just go that
morning and do it. There was, a couple of days before someone had gone and had a walk past in plain clothes, a week or so before someone had gone and had a walk past in plain clothes, curtains were always closed, garden was a mess. [Participant J, Failed Drugs Bust]

Analysing So we expected them to do their consultancy, to provide a formula that could be applied to understanding your business, what are your business rules in terms of how you allocate, you now need to, based on this demand curve, consider reallocating resource and changing your structures, that's what we expected. [Participant C, Organisational Restructure]

Interpreting $\quad$ Verbalising $\quad$ Because that was my reaction, and I was feeding that back... I said to Chief, look at this, this isn't right, and that I wouldn't be surprised if we got some adverse publicity about it, and then by the middle of that week, which I think is only a week or ten days before the actual event, all that adverse publicity hit us. [Participant P, Colour-Matching Event]

Visualising If I can see things and I can picture things on a single piece of paper I'm much more comfortable and then can remember. It's understanding where the person who's trying to tell you something is coming from then interpreting what that is. [Participant V, Neighbourhood Policing]

Rationalising You can't go in and say, just because there's a young couple and a baby, you can't say, well there's no way that this can be linked to drugs, because unfortunately so many people out there, with babies, sell drugs. [Participant J, Failed Drugs Bust]

Integrating $\quad$ Consulting $\quad$ We managed to get somebody from County Council for neighbourhood management to work with us in the team, so we were understanding things differently we went to kind of local politicians, presented it to communities through similar points of contact, so there was a fair bit of consultation. [Participant R, Neighbourhood Policing]

Validating Richard looked at it and thought this doesn't look right. Gone to the Chief with his expert intuition after 10 years, saying you're right it doesn't look right and this is where we're going to go with it. So you've got an inkling of intuition coming through there, with a confirmation at this level. [Participant M, Event Cancellation]

Generating I mean we considered, one, that they pay, the attendees pay themselves, options two, that we actually go to a venue in [...] and just have a drink together, but then when we talked around, do you do that, could we do that in terms of the mix of people who'd be coming together, and another one which was even dodgier, I think, was to pass it back to [...], which is a private company, and ask them to pay. [Participant N, Event Cancellation]

Negotiating We did a lot of horse-trading as it were between each other, I'll have soand-so, and need somebody with this skill set, where can I get them? 
Collaborating

Influencing

Disagreeing

Building consensus
Your skills, how good an investigator are you? Do you want to go and be a detective, are you going to make it realistically, no you're not, well... [Participant E, Organisational Restructure]

You've actually got to get people to want to own it and mind it, because actually it's more of a collaborative team thing in a social context. [Participant R, Neighbourhood Policing]

We managed to persuade local community workers to help us do the meetings, because some communities weren't ready to engage with the police at that time, so they did it on our behalf, and that was another kind of leap of faith for them, as much for us. [Participant R, Neighbourhood Policing]

Once it started to unravel a little bit, there was more discussion, and the last thing that this isn't such a good idea, and then probably there was a divergence of... I was probably still, up to quite a late stage, was still quite keen on saying, "no I think we need to stick with this", and one by one other people were coming over, "I think this might be too much, more trouble than it's worth". [Participant S, Staff Relocation]

We took a view, again round this table, in very quick time, that actually, even though we could justify every penny, we didn't want the publicity, and didn't want to be seen to be criticised last week, as it was a few months ago, and then almost ignore that criticism and still blandly, blithely go on ahead and have our own little conference spending, what is perceived to be tax payers money on having a nice time. [Participant L, Event Cancellation]

\begin{tabular}{ll}
\hline Internalising & $\begin{array}{l}\text { Non-formal } \\
\text { learning }\end{array}$
\end{tabular}

Involving

Communicating This is a very well known incident... [people within this division] all of them will be very well aware of the repercussions this had for the organisation, and would seek to avoid what's happened with this.[Participant F, Failed Drugs Bust]

You'll always get that cohort of people who want to be involved and want to drive in assisting that change, at the other end of the spectrum you'll get those people who will criticise and complain and moan no matter what you actually do but they'll never actually contribute to the process. [Participant B, Organisational Restructure]

The key bit in terms of intuitive leadership is if it's not connected with good communication then it can fail. Because you can't make the connection where you've gone with your intuition into actually why you need to do it in the first place and that's what we ended up doing a lot with trying to talk to people about why. [Participant R, Neighbourhood Policing]

Empowering We empower and entrust our people to do that, which I think is the right thing to do, and when you've got a highly motivated individual, such as Steve, who's got a good track record, you encourage your people to be successful, so there is this delegation and it really is empowerment, trusting our people to go and do a good job. [Participant A, Failed Drugs Bust]

Safeguarding A young couple with a baby, cops burst in, they're handcuffed, and then reputation the realisation we've got it wrong, so it is hugely damaging, it's huge, it is impactive, and it's not a good place to be, and somehow we need to recover that in terms of regaining people's trust and confidence, and of course they will tell their family, they told their story in the newspaper, everyone who bought The Advertiser knew about it, and it was on the local radio as well, so things like that can dent public confidence. [Participant A, Failed Drugs Bust]

Adhering to I think consistency is really important as well, so bringing it back to the
values
values of the organisation, and the way we do business, so that we can values always hang things on values... and do the right thing for the right reasons. [Participant O, Event Cancellation] 
Maintaining We all thought, we kind of felt we needed to do things face-to-face, credibility because otherwise you haven't got the credibility as a management team. [Participant W, Staff Relocation].

Being At the end of the day we got it wrong, put our hands up and accept we got accountable it wrong. [Participant F, Failed Drugs Bust]

Institutionalising Systematising We have engagement strategies, we have neighbourhood policing plans, we have web sites, we have computer packages, to look at problem solving, we have regular processes around the inter communities, types of poster that can go out, everything is regularised now. [Participant R, Neighbourhood Policing]

Adjusting Again there will be minor adjustments as things go, as people move to and from, we've got to keep on top of that, it's a constant process. [Participant D, Organisational Restructure]

\begin{tabular}{ll}
\hline Aggregate dimension: Feedback loop & \\
\hline Reinterpreting & $\begin{array}{l}\text { You've got to keep interpreting the future, even if you've gone with one } \\
\text { decision or one model, say, if everything's changing, how do I keep it up } \\
\text { to date, and I think that's probably where we need to kind of keep }\end{array}$ \\
relooking at, how do we continually evolve this, keep looking at it, and \\
understanding the context to agree with it, so the models will be right, but \\
we've got to keep kind of refining it, to tailor it to the context. \\
[Participant R, Neighbourhood Policing]
\end{tabular}


Table 2: Narratives of intuitive hits and intuitive misses

\section{Intuitive Hit 1: Organisational Restructure}

POA's performance inefficiencies put pressure on the senior officers to restructure the distribution of resources. In the beginning of the process, they brought in external consultants with the intention to analyse the organisation's demand and supply of policing, and to find a 'formula' on which they could apply the allocation of resources. This exclusively analytical approach failed when the consultants, who had no personal experience of policing, could not deliver a workable model for POA. The senior officers realised that they were best suited to undertake this task themselves, and needed to employ their intuitive judgements rooted in their experience and knowledge of the business and management of police resources. However, the decision making process became an arduous task around agreeing on the level of staff that was required in different divisions to operate effectively. Through dialogue and justification, the senior officers developed shared understanding and eventually achieved consensus following tense discussions and lengthy negotiations. Eventually the senior officers' intuitive judgements were successfully embedded within the organisation through the implementation of the restructure which gets adjusted on an on-going basis as the demands of the organisation change. The POA's senior officers described this decision as an 'intuitive hit' as the model they developed was not an outcome of analysis of hard data alone, but mainly based on their extensive experience and knowledge of policing and what they 'felt' was the right thing to do. Knowing the business well helped them build a model that would work in POA, leading to increased effectiveness and efficiency in the organisation.

\section{Intuitive Hit 2: Event Cancellation}

POB's Assistant Chief Constable (ACC) received an event announcement through an incoming email inviting colleagues to a celebratory event that would be paid from the operation budget. As soon as reading the email, the ACC's initial feeling was that this was not right, as he knew immediately that this would cause repercussions in publicity. In order to gather more information and to find out about the background of this invitation, he checked with the Chief Inspector who sent out the email. His rationale did not make sense to the ACC, he thought this would end up being a chaos. He then consulted the Chief Constable (the most senior officer) and the Finance Director (finance expert) to seek their views, and verify his own intuitive judgement. Their collective feeling was that the event should not go ahead, reasoning that they did not want to be seen as having a nice time spending the taxpayers' money. They considered other options where everyone would pay for their own dinner, but not having received enough support, the event got cancelled eventually. This decision was considered to be an 'intuitive hit' by the chief officers of POB, attributing to the fact that the ACC intuitively recognised a potential problem and followed his gut feeling by acting on it in a timely manner. Deciding in quick time to cancel the event prevented adverse publicity which would potentially harm the organisation's reputation. The collaboration of the chief officers and the consensus in their intuitions was imperative in this decision as it has allowed for a smooth decision making process in order to respond to the situation swiftly.

\section{Intuitive Hit 3: Neighbourhood Policing}

The UK Government initiated a directive to all police forces in the country to establish 'neighbourhood policing' in their respective counties. This was a new concept at the time, and the senior officers at POC were told to design and deliver their own model without much guidance. The Chief Superintendent and the Chief Inspector who were leading this project, looked at some of the analytical data available from national pilots but mainly had to rely on their intuitive knowledge to determine the model of engagement with the public that would work best in their county. Initially, the Chief Superintendent tried to visually explain his vision of neighbourhood policing to the Chief Inspector by drawing the model in his mind on the board. Together they engaged in interpreting this model whereby the key element was to let the public determine the priorities that the police would tackle. It was clear to them that they needed to take this intuitive leap. However, they had to rationalise their shared intuition in order to be able to 'sell' this idea to the rest of the organisation and to the external partners. Establishing structures, systems and strategies around this model facilitated the successful implementation of neighbourhood policing. This model has become an on-going project whereby it gets adjusted based on the changes in the demands and operating context of the organisation. The decision was deemed an 'intuitive hit' which enabled a positive move away from focusing solely on the organisation to responding to public's priorities which eventually led to increasing satisfaction figures in the communities. 
Table 2: Narratives of intuitive hits and intuitive misses (cont.)

\section{Intuitive Miss 1: Failed Drugs Bust}

POA officers had been receiving on-going intelligence about drugs activity at a certain address from various sources and this address was going to be targeted on a week of action. Prior to the operation, the Police Constable (PC) who was leading the operation went to the address to check if there was any activity. Looking at the house, the PC's gut feeling, based on his previous experience, verified the information they were receiving. He explained that the curtains were always closed, the garden was a mess and from what it looked, the state of the address matched the prototype he had in his mind. PC and his team were highly experienced officers in executing search warrants and had high success rates. As far as they were concerned they were just attending a routine job. On the operation day, the team forced entry into the house, two people in the address were detained and handcuffed as they would do in every arrest. However, as soon as the Sergeant entered the house, her immediate gut feeling was that this was not the right place. She explained that seeing the young couple and a baby she immediately knew these were not the subjects they were looking for. Later on, it became apparent that the subjects of the search had moved out of this address some time ago but continued giving this address as their current residence. Evidently, information received by the intelligence unit appeared to be current but in fact it was incorrect. It also transpired that the intelligence unit had not carried out a comprehensive investigation on the address due to a large number of searches that week. This incident led to a damaging story on the front page of the local newspaper the next day, creating a PR nightmare for the senior team and great embarrassment for the operations team. This was clearly an 'intuitive miss' whereby acting on inaccurate information led to an unsuccessful outcome. The officers reflected that more thorough investigation should have been carried out before the address was targeted that week.

\section{Intuitive Miss 2: Colour-Matching Event}

A female support group at POB announced that a 'Health and Wellbeing Day' was being organised. They sent out an organisation-wide email outlining the programme for the day which included a 'colour-matching' session whereby the female police officers would be advised on what colours to wear to 'look their best'. When the HR Director heard of this particular session, she said, she was horrified and had a strong gut feeling that this was going to create very bad publicity for the organisation. She then took this matter to the chief officers' meeting and explained that this session was not appropriate. However, the other female member of the SMT, the Assistant Chief Constable (ACC), felt differently about this. Her argument was that they ought to support this session because, based on her personal experience, it was important in terms of empowering women to feel confident in a male-dominated organisational culture. By presenting her firm position the ACC influenced everyone and it was eventually agreed for this session to carry on at the event. In the meantime, the news about POB women police officers 'doing their colours' quickly spread into the media with damaging comments. In response, the chief officers immediately took a decision to cancel this session. This decision was perceived as an 'intuitive miss' in that although the HR Director's gut feelings were right, the chief officer group did not follow her intuition; they had been persuaded by the ACC's counter-argument. In hindsight, the HR Director suggested she should have trusted her initial intuition and also been more assertive. On the other hand, the ACC reflected that they should have taken their time and made a more informed decision, by analysing the situation, instead of making a quick judgment call.

\section{Intuitive Miss 3: Staff Relocation}

During the assessment process for crime management at POC, several issues transpired in two policing areas which highlighted poor management by the Sergeants in charge of those areas. The Chief Inspector who directly managed these Sergeants knew that something needed to be done quickly in those particular areas where the public had low confidence in the police. He took this matter to the SMT to consult their view. The collective feeling of the SMT was that they needed to work on the weak links which were the two Sergeants. Quickly it was decided to move these Sergeants to different locations where they would be provided with more support, and to replace them by other Sergeants who were known to be effective within the organisation. They discussed about options for suitable candidates to swap places with these Sergeants. They then approached these Sergeants to tell them about the SMT's plan to move them. But both Sergeants refused this decision, making the SMT look weak in terms of not being able to implement their decisions, which in turn weakened the SMT's ability in improving the effectiveness of the organisation. As a result of this experience, the SMT established the 'Talent Management Scheme', a development programme for officers who would like to advance within the organisation, which also assured the SMT that the officers on this scheme would be willing to do what the SMT requested from them. This decision was an 'intuitive miss'. On reflection, the senior officers expressed that the failure came about as they wanted a quick solution to the problem, whereas the right approach would have been to evaluate the situation in consultation with the Sergeants in a more informed manner. 
Figure 1: Feed-forward and Feedback Loop Processes of Organisational Learning

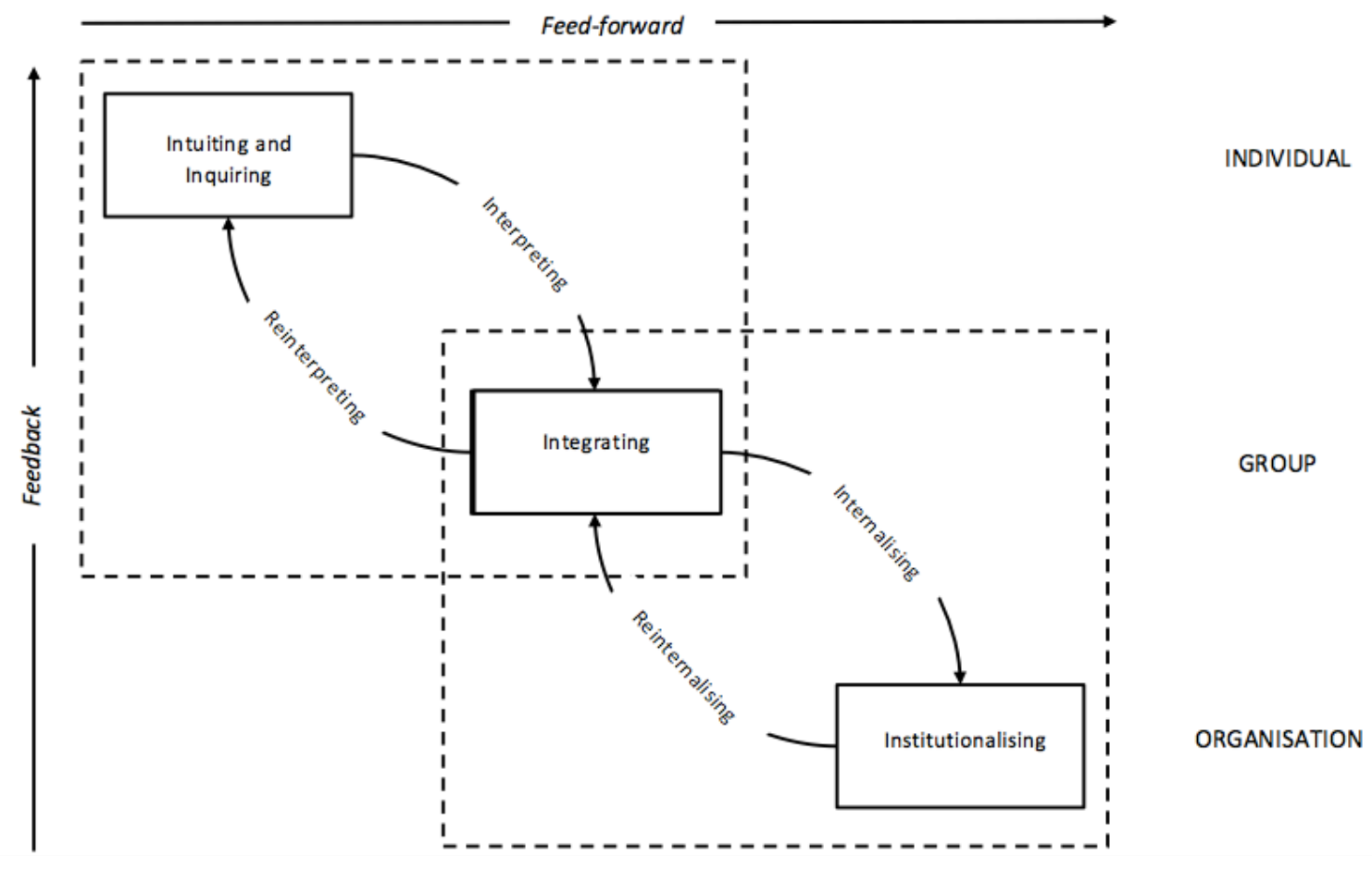

